\title{
RECONSTRUCTION METHODS OF THE HEAD DEFECTS AFTER SKIN CANCER EXCISION - CASE SERIES
}

\author{
Raluca GRIGORE ${ }^{1,2}$, Anca I. CIRSTEA ${ }^{1 凶}$, Paula PASCU BEJENARU², \\ Catrinel B. SIMION-ANTONIE ${ }^{1,2}$, Gloria S. MUNTEANU ${ }^{2,3}$, Mihnea CONDEESCU-COJOCARITA ${ }^{1,2}$, \\ Serban V.G. BERTESTEANU ${ }^{1,2}$
}

${ }^{1}$ ENT Department, Coltea Clinical Hospital, Bucharest, Romania

2 "Carol Davila" University of Medicine and Pharmacy, Bucharest, Romania

${ }^{3}$ Central Military Emergency Hospital "Dr. Carol Davila”, Bucharest, Romania

Received 14 March 2021, Accepted 01 May 2021

hitps://doi.org/10.31688/ABMU.2021.56.2.13

\begin{abstract}
Introduction. Cancer surgery often involves excisions that lead to important anatomical defects. The reconstruction methods following an ablative surgery for head skin cancer are unique and require special attention for both shape and function. Utilisation of split-thickness or full-thickness skin grafts is indicated for face regions with minimal motion.
\end{abstract}

Case presentations. We present four cases of skin cancer, who required a flap for the reconstruction of post-excision defects. The first case is of a 90-year-old male with a right preauricular squamous cell carcinoma. The remaining defect after tumour ablation was reconstructed with a full-thickness skin graft harvested from the arm. The second case is of a 45-year-old male with a malignant melanoma of the scalp. The defect on the scalp was also covered with a skin graft. The third case is of a 51-year-old diabetic woman with left nasal skin cell carcinoma. The defect left after excision was reconstructed with a nasolabial flap and a free cartilage graft harvested from the concha. The fourth case is of a 65-year-old male with a basal cell carcinoma of

\section{Résumé}

Méthodes de reconstruction des défauts de la tête après excision du cancer de la peau - série de cas

Introduction. La chirurgie du cancer implique souvent des excisions qui conduisent à des défauts anatomiques remarquables. Les méthodes de reconstruction suite à une chirurgie ablative pour un cancer de la peau de la tête sont uniques et nécessitent une attention particulière, tant pour la forme que pour la fonction. Lutilisation de greffes de peau d'épaisseur fractionnée ou peu pleine épaisseur est indiquée pour les parties du visage avec un mouvement minimal.

Présentations de cas. Nous présentons quatre cas de cancer de la peau nécessitant un lambeau pour la reconstruction des défauts post-excision. Le premier cas est celui d'un homme de 90 ans atteint d'un carcinome épidermoïde préauriculaire droit. L'ablation de la masse tumorale cutanée pré-auriculaire droite a été réalisée et le défaut restant a été reconstruit avec une greffe de peau pleine épaisseur prélevée du bras. Le deuxième cas est d'un patient de 45 ans avec un 
the nose. The aesthetic result at a distance, after nasolabial flap reconstruction, was very good.

Conclusions. The nasolabial flap is reliable, plastic and perfectly suited to the one-step reconstruction of fascio-cutaneous material losses. Age does not affect the graft viability, but control of comorbidities, such as diabetes, are extremely important when using cartilaginous grafts.

Keywords: flaps, skin graft, skin cancer.

\section{List of abbreviations:}

BCC - basal cell carcinoma

SCC - squamous cell carcinoma mélanome malin du cuir chevelu. Le défaut du cuir chevelu a également été recouvert d'une greffe de peau. Le troisième cas est celui d'une femme diabétique de 51 ans, atteinte d'un carcinome cutané nasal gauche. Le défaut laissé après l'excision a été reconstruit avec un lambeau nasolabial et une greffe de cartilage libre prélevée du conque. Le quatrième cas est celui d'un homme de 65 ans atteint d'un carcinome basocellulaire du nez. Le résultat esthétique à distance, après reconstruction par lambeau nasogénien, était très bon.

Conclusions. Le lambeau nasolabial est fiable, plastique et parfaitement adapté à la reconstruction en une étape des pertes de matière fascio-cutanée. L'âge n'affecte pas la viabilité du greffon, mais le contrôle des comorbidités, telles que le diabète, est extrêmement important lors de l'utilisation de greffes cartilagineuses.

Mots-clés: lambeaux, greffe de peau, cancer de la peau.

thickness of around $1 \mathrm{~mm}$. For its nutrition, the dermis must be in contact with the recipient site, so subcutaneous fat should not be left on the undersurface of the graft and must be carefully removed.

The rotation flap is the most commonly used type of flap. A condition needed for its use is that the skin in the donor area must be sufficiently mobile to be able to cover the secondary defect. If the base of the flap is too narrow, there is an increased risk of flap necrosis ${ }^{6}$.

\section{Cases presentation}

We present four cases of skin cancer, who required a flap for the reconstruction of post-excision defects. The patients were treated in the Otorhinolaryngology Department of the Coltea Clinical Hospital, Bucharest (Romania), between 2019-2021.

Patients' demographic data were collected, and the outcomes measured included flap survival and complications. A prospectively maintained tumour board database, electronic medical records including case records, surgical details, and follow-up data were studied. Postoperative functional and oncological outcome were also analysed.

All patients signed an informed consent.

\section{Case 1}

A 90-year-old male patient, diagnosed with a right preauricular SCC seven months before, with a progressive increase in size during the last two years, has presented to our clinic. He followed 30 sessions of radiotherapy, the last four months before the presentation 


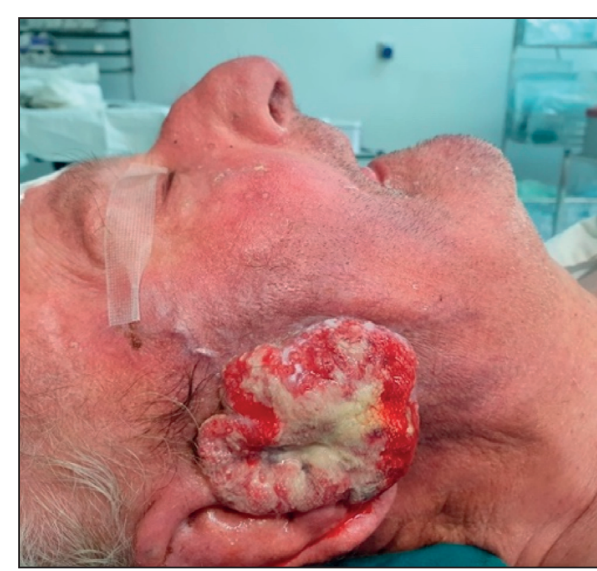

Figure 1. Right preauricular tumour mass

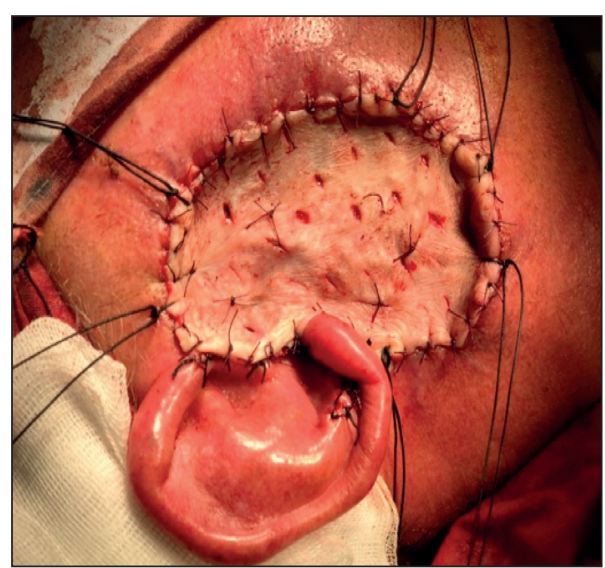

Figure 2. Skin graft

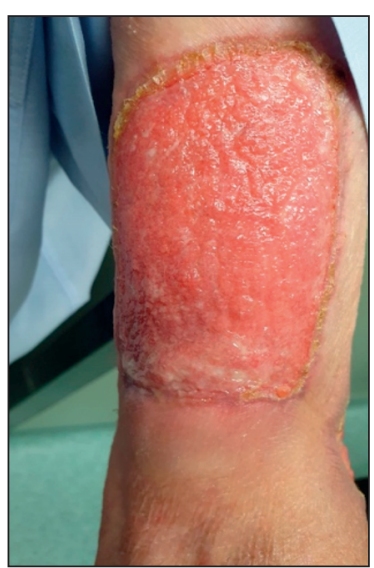

Figure 3. Donor region from the arm - one month after surgery

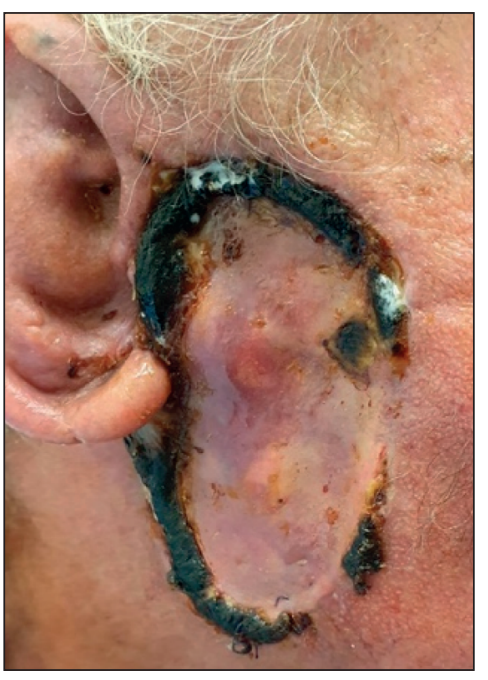

Figure 4. Skin graft 2 weeks after surgery

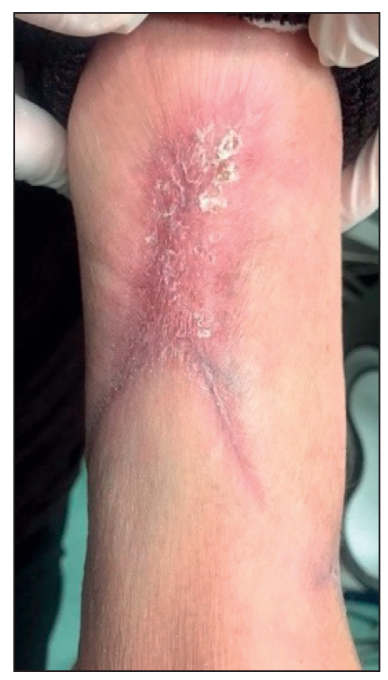

Figure 5. Donor wound healed -8 months after surgery

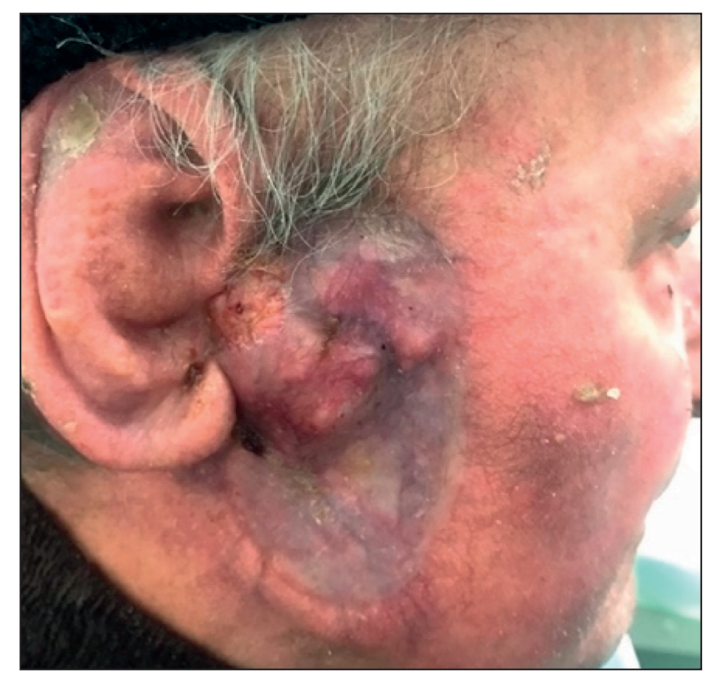

Figure 6. Viable graft with local recurrence 8 months after surgery in our clinic. The patient's past medical history includes polycythemia vera, treated with hydroxycarbamide, arterial hypertension and an ischemic stroke.

The clinical examination of the head and neck revealed a right preauricular vegetative and ulcerated tumour mass, about $3 / 5 \mathrm{~cm}$ in size, with areas of necrosis, adherence to deep plans, which came in contact with the pavilion of the left ear (Figure 1). The right external auditory canal was collapsed and sero-mucous secretions flowed from it. Methicillin-resistant Staphylococcus aureus and Acinetobacter baumanii were isolated from the ear secretion. Antibiotic therapy guided by antibiogram was initiated. The imaging examinations did not describe lymph node metastasis.

The ablation of the right preauricular skin tumour mass was performed, along with a superficial parotidectomy, and the remaining defect was reconstructed with a full-thickness skin graft harvested from the arm. The postoperative histopathological examination revealed infiltration of the deep resection margin at the parotid level. Figure 2 shows the skin graft anchored with a discontinuous suture and the crusting, made to provide the drainage of serous secretion from beneath the graft. The long wires were used to anchor the tie-over compression bandage, that was held in his position for five days. Nitrogylcerin spray was applied daily on the skin graft, after the tie-over bandage was removed. Figure 4 presents the well-coloured and textured skin graft two weeks after surgery. The arm wound was allowed to granulate (Figure 5). The dressing at this level was made with betadinate solution and antibiotic ointment and was changed every two days. The evolution of the flap was favourable, but the patient developed a local recurrence, 8 months after surgery (Figure 6). 


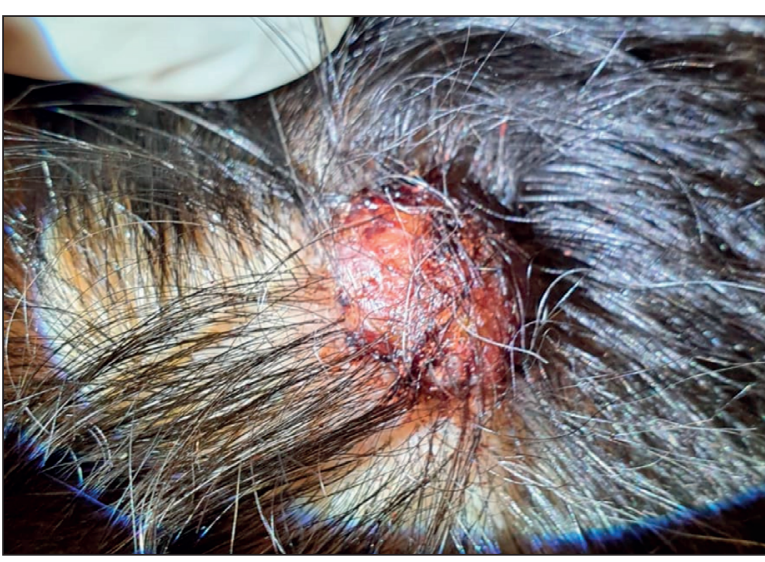

Figure 7. Melanoma of the scalp

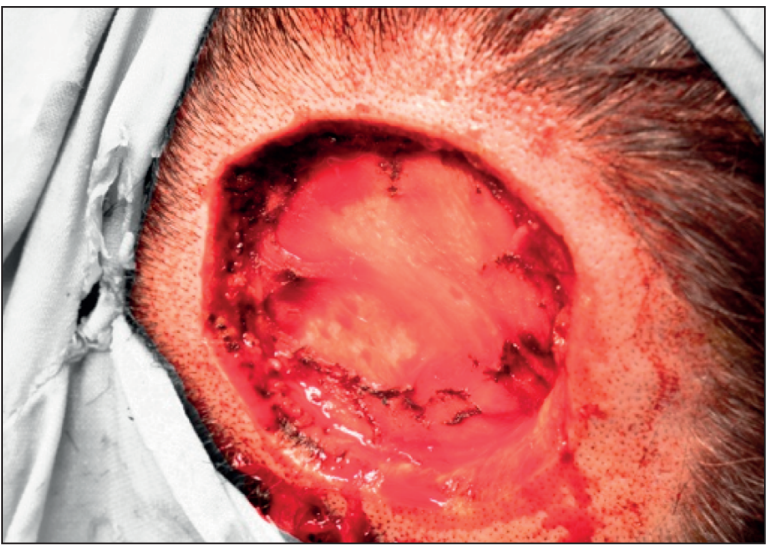

Figure 9. The surgical defect

\section{Case 2}

The second case is of a 45-year-old male patient, who initially presented to the hospital for left latero-cervical lymphadenopathy. The patient's past medical history includes type 2 diabetes.

A left selective neck dissection was performed and the extemporaneous biopsy revealed an undifferentiated SCC metastasis of the lymph nodes. The immunohistochemical examination established the final diagnosis of melanoma lymph node metastasis. After a thorough inspection of the whole body, a left parietal scalp nodule was found (Figure 7), measuring $3 \times 2 \mathrm{~cm}$, approximately $1.5 \mathrm{~cm}$ in height and $1 \mathrm{~cm}$ in thickness. The scalp was shaved to expose the area to be excised. A circumferentially incision was made in the scalp, with a safety margin of $1 \mathrm{~cm}$ on each side of the lesion. The dissection was made until the plane between the galea aponeurotica and the periosteum of the skull was reached (Figure 8).

The surgical defect shows the periosteum of the scalp, which will be the bed to receive a full-thickness skin graft (Figure 9). The skin graft was harvested from the left arm (Figure 10).

The skin graft was sutured with continuous interlocking absorbable suture material (Figure 11).

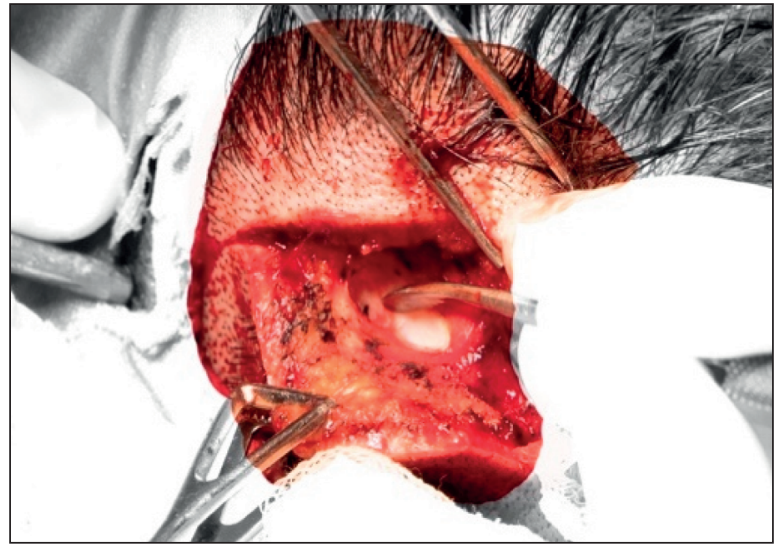

Figure 8. Dissection up to the periosteum

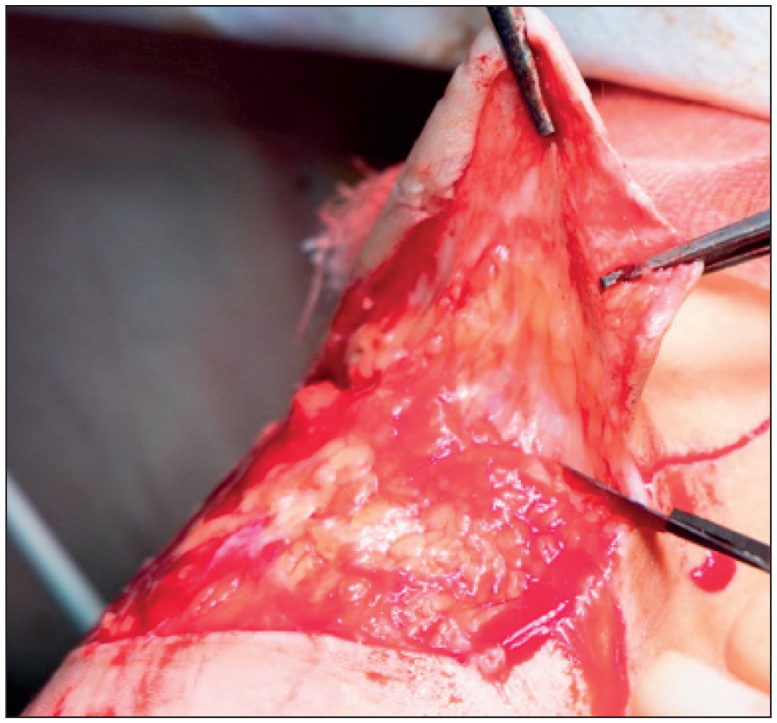

Figure 10. Harvest of the skin graft

Several buttonholes were made in the center of the graft, to facilitate the drainage of serous material from beneath the graft (Figure 12). The skin graft was apposed against the periosteum with a pressure dressing secured by silk sutures taken at the periphery of the surgical defect, and tied over the dressing (Figure 13). The tie-over bandage was removed after five days (Figure 14).

The appearence of the skin graft three weeks after surgery is shown in Figure 15. The graft has healed well and adequate graft coloration can be observed.

\section{Case 3}

A 51-year-old female patient, known with arterial hypertension and type 2 diabetes, presented with a friable tumour over left ala of nose since two years, gradually progressive. On local examination, the lesion was $2 \mathrm{x} 1 \mathrm{~cm}$, firm, black, slightly tender, and bled on touch (Figure 16). No palpable lymph nodes on clinical examination. The histopathology report revealed a BCC. 


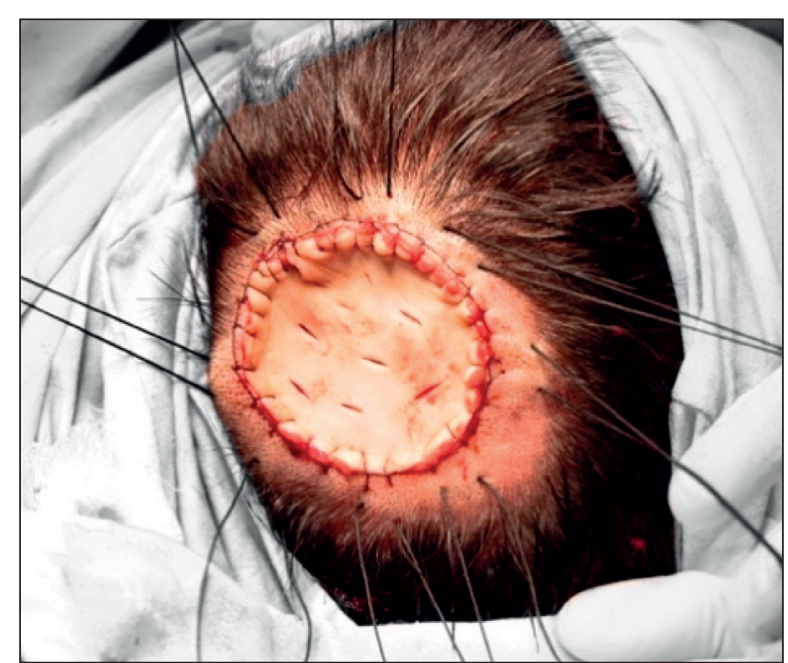

Figure 11. Skin graft sutured with continuous interlocking sutures

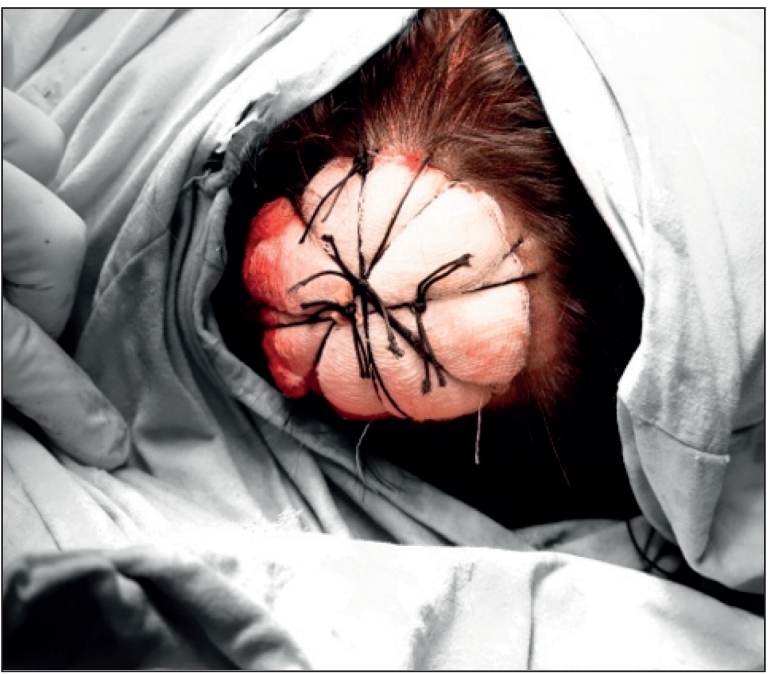

Figure 13. Tie-over dressing

The plan of surgical excision requiring a through-and-through resection of the ala of the nose, including the underlying mucosa, and a proposed nasolabial flap for reconstruction of the surgical defect, that would provide external and inner lining, is shown in Figure 17. The defect remaining after excision is shown in Figure 18. A free cartilage graft harvested from the ear was used to restore the structural support (Figures 19 and 20). The donor site defect was closed primarily by appropriate mobilization and the nasolabial flap was sutured with a discontinuous suture (Figure 21).

The oncological result was good, but because of neglected diabetes mellitus the patient developed a cartilaginous graft necrosis, which compromised the shape of the nose. In Figure 22 it is shown the result three months after surgery, with asymmetry of the left nostril after losing the cartilaginous graft.

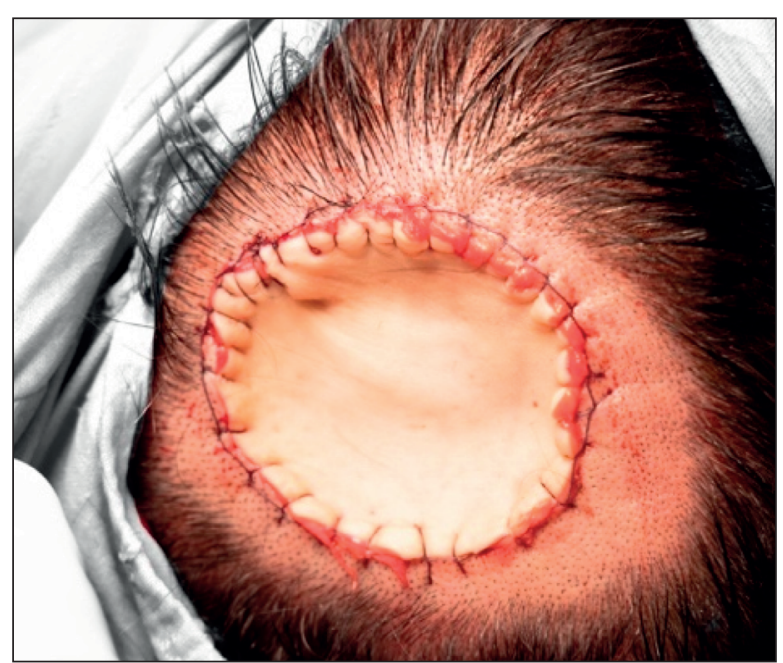

Figure 12. Buttonholes and peripherals silk sutures

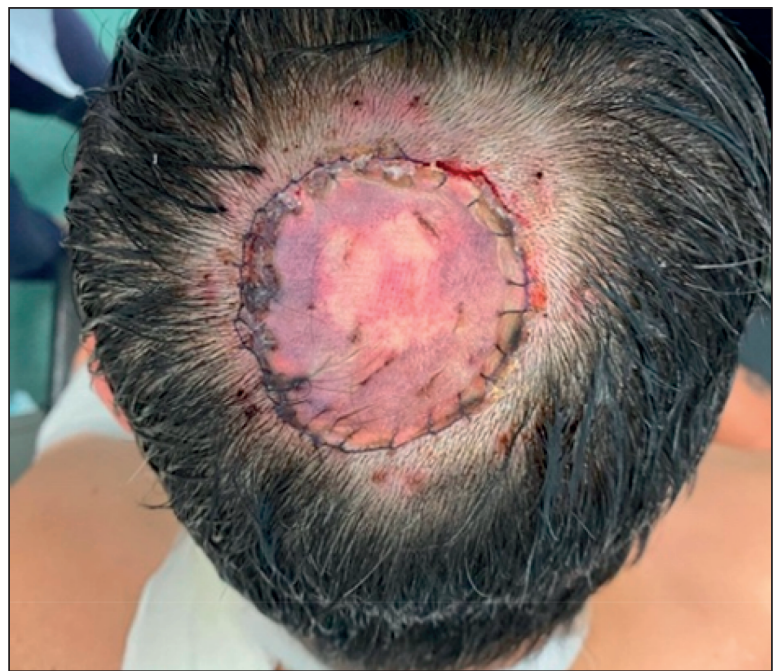

Figure 14. Skin graft after removing the compressive dressing - five days after surgery

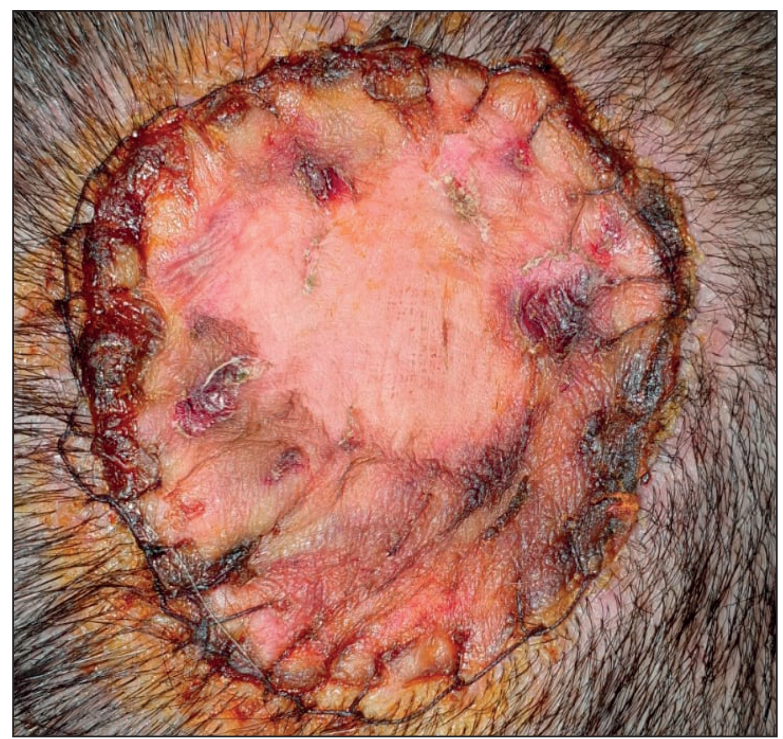

Figure 15. Skin graft - three weeks after surgery 


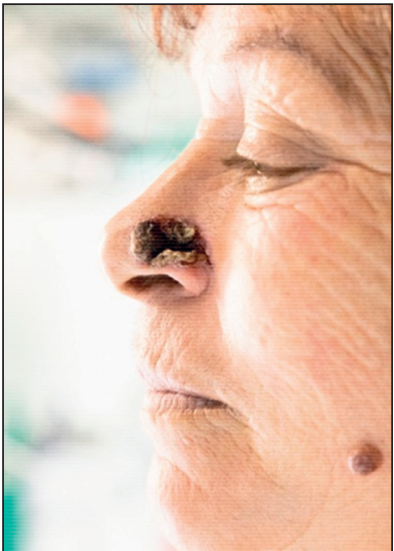

Figure 16. Basal cell carcinoma of the nose

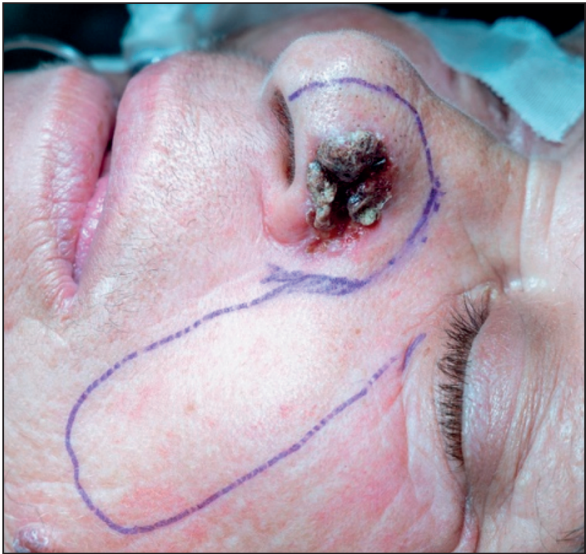

Figure 17. Drawing the nasolabial flap

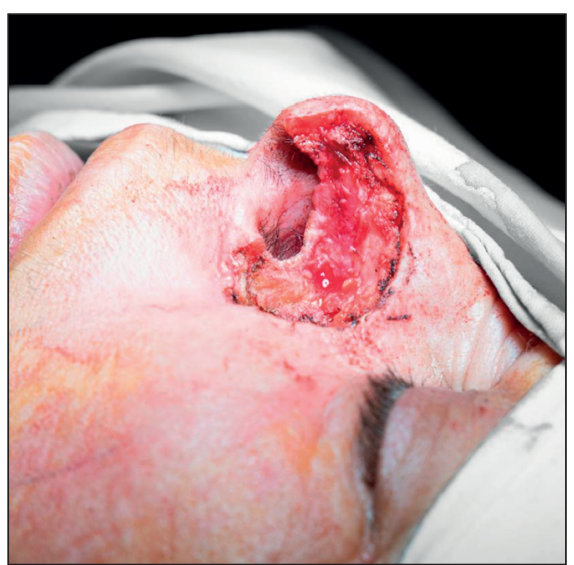

Figure 18. Partial absence of alar cartilaje after excision

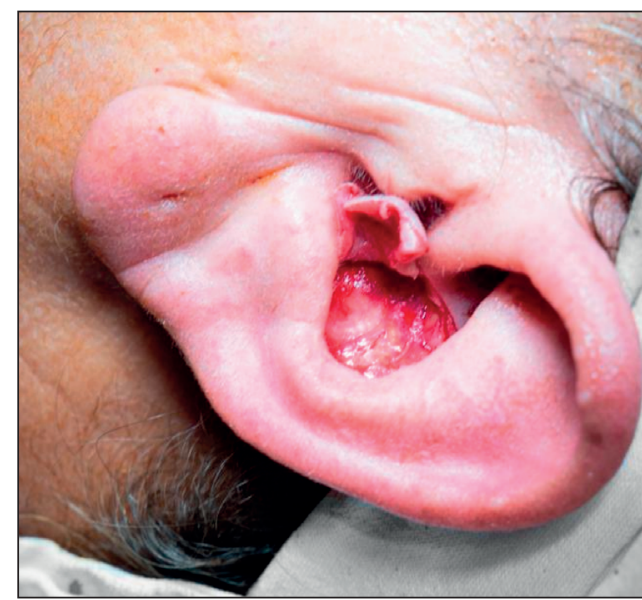

Figure 19. Harvesting the cartilage from the concha

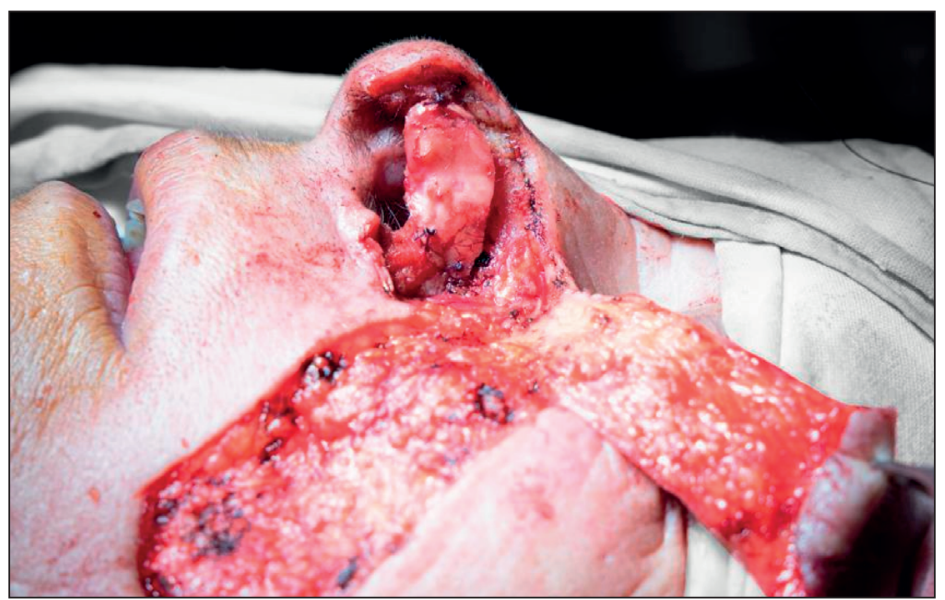

Figure 20. Harvesting the cartilage from the concha

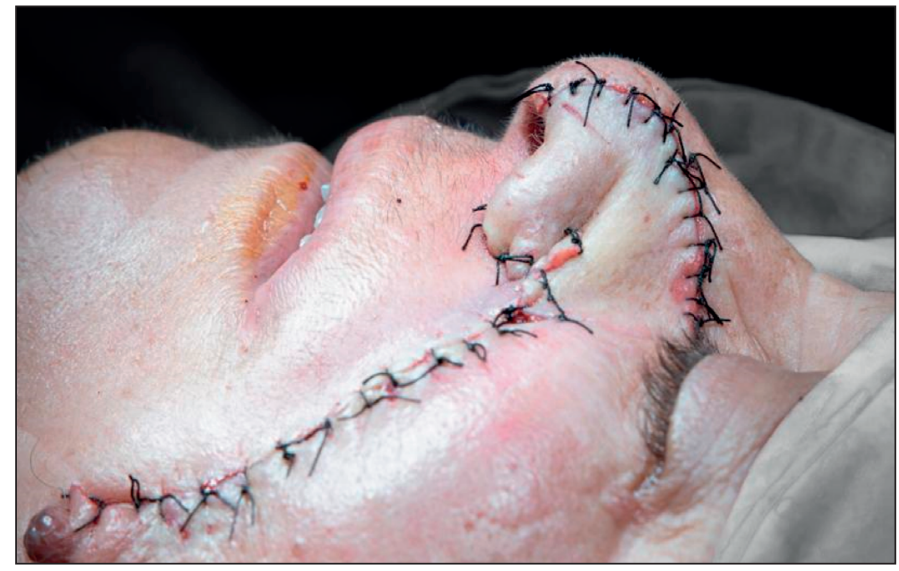

Figure 21. Nasolabial flap and donor site sutured

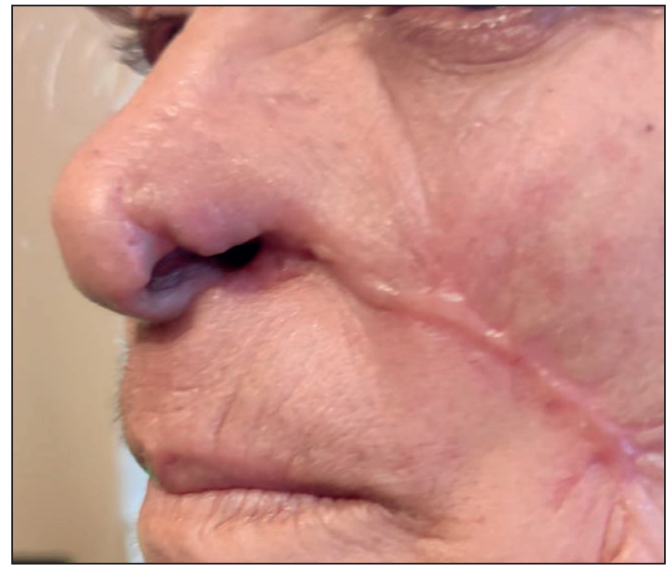

Figure 22. Three months after surgery

\section{Case 4}

A 65-year-old male with arterial hypertension presented for the appearance of a lesion on the tip of the nose, one year before, which gradually increased in size. The histopathology report revealed a BCC. Both alar cartilages and the dorsal portion of the septum were visualized after the excision of the lesion (Figure 23). The remaining defect was reconstructed with a nasolabial flap (Figure 24). Several months after surgery, an excellent cosmetic result was obtained (Figure 25). 


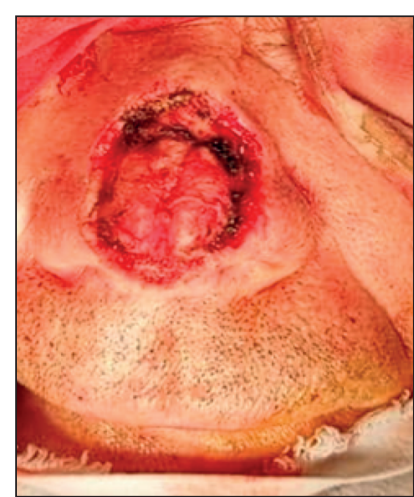

Figure 23. Alar cartilages and septum

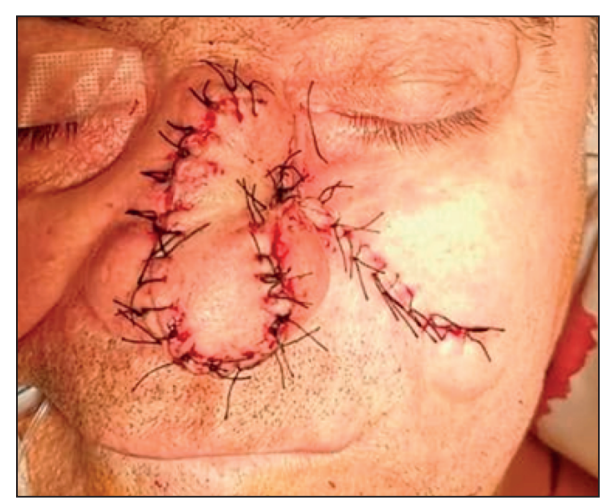

Figure 24. Alar cartilages and septum

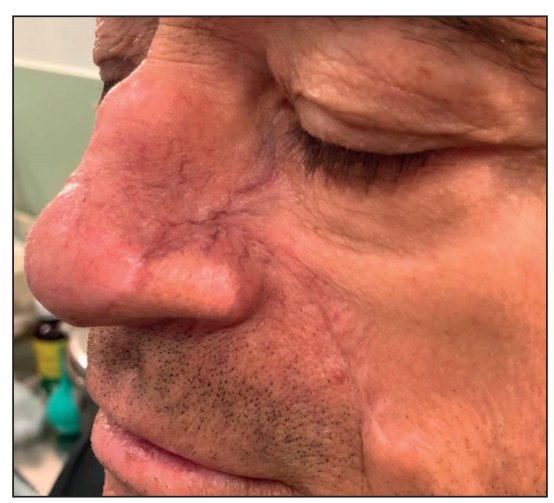

Figure 25. Excellent cosmetic result one year after surgery

\section{Discussion}

The goal of reconstructing a loss of substance in the face is to allow the most natural restoration possible, by replacing each tissue with its best equivalent. All patients had their sutures removed at ten days. In the third case, of the woman with uncontrolled diabetes, a dehiscence of the wound at the donor site appeared during the first days, after the sutures were removed.

Full-thickness skin grafts are ideal for visible areas of the face, inaccessible by local flaps, or when local flaps are contraindicated. They retain more characteristics of the normal skin, including colour, texture, and thickness, when compared with split-thickness grafts. Full-thickness grafts also undergo less contraction while healing. Revascularization of the graft begins 2-3 days postgrafting. Contraction of the skin graft begins shortly after initial wounding, progressing slowly over 6-18 months following grafting. To prevent hyperpigmentation, the graft should be protected from direct sunlight for at least six months. Full-thickness grafts may be harvested from the upper eyelid, nasolabial fold, preauricular and postauricular regions, and supraclavicular fossa? ${ }^{7}$. In the cases presented, a larger area of skin was needed to cover the remaining defects, so the elbow crease was used. There was a good vascularization of the graft after removing the tie-over dressing. Vascularization was subsequently increased by the use of nitroglycerin spray. Coto-Segura et al. show that the spray is more effective when used every six hours and could enhance the survival of skin grafts and flaps that show signs of injury, or as prevention in high-risk patients, such as smokers or patients with diabetes ${ }^{8}$.

Reconstructing the nose is an aesthetic challenge due to the alternating concave and convex surfaces, which are divided into subunits and separated by depressions and elevations of the skin. For defects involving the nasal cartilage, the restoration of the nasal framework is crucial for maintaining nasal projection. In these cases, autologous transfer of septal, auricular, or costal cartilage should be performed ${ }^{9}$.

The nasolabial flap is a musculo-cutaneous flap pedicled over the facial artery. The flap extends from the canthus to the lower part of the nasolabial fold ${ }^{10}$. The nasolabial folded flap can be used to reconstruct a loss of transfixing substance from the nasal wing ${ }^{11}$. The cartilage used to replace the ala is mainly carried out at the level of the concha, due to easier access and its naturally convex shape which recreates the curvature of the nostril ${ }^{12}$. In our cases, the shape of the nose has been very well redefined with this type of flap.

In the third case, in whom the auricular cartilage was necessary for reconstruction, the necrosis of the cartilage led to the loss of the structural support of the flap, with deformation of the left nostril over time. The free cartilage must be sutured to the vascularized lining of the nose and covered with a vascularized flap for external cover, like in our case the folded nasolabial flap. To ensure survival, the vascularized tissue should nourish both sides of the cartilage. Failure to adequately repair or reconstruct the internal nasal lining may lead to graft necrosis ${ }^{13}$.

Metastatic cutaneous SCC of the parotid gland is an aggressive neoplasm that requires combination therapy. The presence of a lesion larger than $6 \mathrm{~cm}$ or facial nerve involvement are associated with a poor prognosis ${ }^{14}$. There is no consensus regarding the definition of acceptable surgical margins for $\mathrm{SCC}^{15}$. The studies made by Hinerman and Iyer show that postoperative radiotherapy decreases the rate of recurrence in patients with infiltrated resection margins $^{16,17}$. Another study suggests that the resection of positive margins in metastatic cutaneous SCC of the parotid gland may not be necessary, and the radiation therapy is the main treatment for positive margins ${ }^{18}$. Although the postoperative histopathological examination revealed infiltration of the deep resection margin at the parotid level in our first case, radiotherapy 
could not be performed, because the patient had received the maximum allowed dose, preoperatively. To date, surgery is still considered as the gold standard therapeutic approach of invasive cutaneous SCC ${ }^{19}$.

\section{Conclusions}

The main objective of the treatment of head skin cancers is the elimination of the tumour with maximal preservation of physical appearance and function. The nasolabial flap is reliable, very plastic and perfectly suited for the one-step reconstruction of fascio-cutaneous material losses. The age does not influence the graft viability, but comorbidities such as diabetes may have an impact on the outcome, when using cartilaginous grafts.

\section{Author Contributions:}

R.G., S.B., C.S.A., G.M., A.C. and M.C.C. were responsible for the diagnostic procedures, clinical diagnosis, and treatment decisions and R.G. performed the surgery. A.C. and P.P.B. wrote the manuscript. All authors have read and agreed to the published version of the manuscript.

\section{Compliance with Ethics Requirements:}

"The authors declare no conflict of interest regarding this article"

"The authors declare that all the procedures and experiments of this study respect the ethical standards in the Helsinki Declaration of 1975, as revised in 2008(5), as well as the national law. Informed consent was obtained from the patients included in the study"

"No funding for this study"

\section{Acknowledgements:}

None

\section{References}

1. Bernardini N, Skroza N, Zuber S, et al. Face and scalp basal cell carcinoma treatment: a review of the literature. Acta Dermatovenerologica Croatica 2019;27(1): 22-27.

2. Najjar T. Cutaneous squamous cell carcinoma. Otolaryngology and Facial Plastic Surgery. https://emedicine.medscape.com/. (Accessed on February 10, 2021)

3. Shashanka R, Smitha B. Head and neck melanoma. ISRN Surgery. 2012;2012:948302.

4. Zito PM, Scharf R. Melanoma of the head and neck. [Updated 2020 Sep 29]. In: StatPearls [Internet]. Treasure
Island (FL): StatPearls Publishing; 2021. Available from: https://www.ncbi.nlm.nih.gov/books/NBK513248/ (Accessed on February 12, 2021)

5. Shah J, Patel S, Singh B. Scalp and skin. Jatin Shah's Head and Neck Surgery and Oncology, 4th ed, Elsevier. Philadelphia, USA, 2012:21-68.

6. Theissing J, Werner JA, Rettinger G. Reconstructive plastic surgery of the face. ENT-Head and Neck Surgery: Essential Procedures, $1^{\text {st }}$ ed, Georg Thieme Verlag, Stuttgart, Germany, 2011:9-44.

7. Khosh MM, Shohet MR. Full-thickness skin grafts. Otolaryngology and Facial Plastic Surgery. https://emedicine. medscape.com/article/876379-overview (accessed February 21, 2021)

8. Coto-Segura P, Ingelmo J, Alonso T, Sánchez-Sambucety P, Rodríguez-Prieto MA. Effectiveness of topical application of nitroglycerin spray to increase survival of cutaneous flaps and grafts. Actas Dermo-Sifiliográficas. 2007: 291-295.

9. Badash I, Shauly O, Lui CG, Gould DJ, Patel KM. Nonmelanoma facial skin cancer: a review of diagnostic strategies, surgical treatment, and reconstructive techniques. Clinical Medicine Insights: Ear, Nose and Throat. 2019;12(1):1-10.

10. Wright H, Stephan S, Netterville J. Nasolabial flap for oral cavity reconstruction. Open Access Atlas of Otolaryngology, Head $\mathcal{E}$ Neck Operative Surgery. Ed. Fagan J, 2017:1-11.

11. Pers M. Cheek flap in partial rhinoplasty:a new variation, the in and out flap. Scandinavian Journal of Plastic and Reconstructive Surgery. 1967;1(1):37-44.

12. Bouhanna A, Bruant-Rodier C, Himy S, et al. Reconstruction of the nostril wing by Burget's upper-pedicle nasogehnus flap: about seven cases. Annals of Aesthetic Plastic Surgery. 2008:272-277.

13. Bloom JD, Ransom ER, Miller CJ. Reconstruction of alar defects. Facial Plastic Surgery Clinics of North America. 2011; 19(1) :63-83.

14. Audet N, Palme CE, Gullane PJ, et al. Cutaneous metastatic squamous cell carcinoma to the parotid gland: analysis and outcome. Head Neck. 2004; 26(8):727-32.

15. Vasconcelo L. Invasive head and neck cutaneous squamous cell carcinoma: clinical and histopathological characteristics, frequency of local recurrence and metastasis. Anais Brasilerios De Dermatologia. 2014;89(4):562-568.

16. Hinerman RW, Indelicato DJ, Amdur RJ, et al. Cutaneous squamous cell carcinoma metastatic to parotid-area lymph nodes. Laryngoscope. 2008;118(11):1989-1996.

17. Iyer NG, Clark JR, Murali R, Gao K, O’Brien CJ. Outcomes following parotidectomy for metastatic squamous cell carcinoma with microscopic residual disease: implications for facial nerve preservation. Head Neck. 2009;31(1):21-27.

18. Makki F, Mendez A, Taylor S. Prognostic factors for metastatic cutaneous squamous cell carcinoma of the parotid. Journal of Otolaryngology - Head E Neck Surgery. 2013; 42(1): 14 .

19. Bernardini N, Balduzzi V, Losco L, et al. A review of the literature of surgical and nonsurgical treatments of invasive squamous cells carcinoma. BioMed Research International. 2018:1-9. 